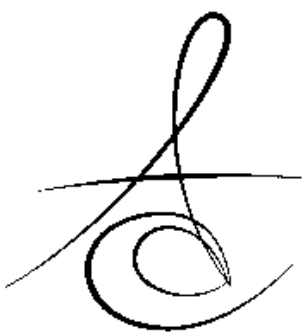

\title{
POLİETER ETER KETON (PEEK) ve DENTAL KULLANIMI
}

POLYETER ETHER KETONE (PEEK) AND ITS DENTAL USE ${ }^{*}$

\author{
Doç. Dr. Ahmet Kürşad ÇULHAOĞLU* Doç. Dr. Serhat Emre ÖZKIR ${ }^{* *}$ \\ Arş. Gör. Fatoş TÜRKKAL ${ }^{*}$
}

Makale Kodu/Article code: 3536

Makale Gönderilme tarihi: 25.12.2017

Kabul Tarihi: 16.07.2018

\section{ÖZET}

Poliaril eter keton ailesinin yüksek ISI polimeri olan polieter eter keton (PEEK) semikristalin bir termoplastiktir. Yüksek mekanik fiziksel özelliklere, aynı zamanda termal ve boyutsal stabiliteye sahip PEEK, birçok endüstri alanında metallere alternatif görülen ender polimerlerdendir. Yüksek aşınma direncine sahip olan ve kimyasal ajanlara karşı dayanıklı bir materyal olan PEEK, uygun biyomekanik özellikleri, uzun ömürlü oluşu ve biyouyumluluğu ile 1990'ların sonunda özellikle medikal alanda, ortopedide metal bileşenli implantlara alternatif olarak kullanılmaya başlanmıştır. Kemiğe yakın elastik modülü ile implant materyali olarak da kullanılan bu materyal, dental alanda özellikle de protetik diş tedavilerinde kullanılmaya başlanmıştır. Bu derlemede PEEK materyalinin yapısı, özellikleri ve dental kullanım alanları anlatılmıştır.

Anahtar Kelimeler: Polieter Eter Keton (PEEK), Termoplastik, Protez

\section{ABSTRACT}

Polyether Ether Ketone (PEEK), is a semi-crystalline high-temperature thermoplastic polymer in polyaryl ether ketone family. PEEK of high mechanic and physical features, thermal and dimensional stability, is one of rare polymers seen as an alternative to metal materials in many industrial fields. With its features like, high-corrosion and chemical resistance and compatible biomechanic features, long-life and biocompatibility, PEEK began to be used especially in medicine as high-performance thermoplastic material alternative to metal-composite implants in orthopedics in the late 1990's. PEEK is used as an implant material, because of its elasticity module. That's why it is used as a prosthetic material in dentistry. In this study, the structure, general features and the use of PEEK material are explained.

Key Words: Polyether Ether Ketone (PEEK), Thermoplastic, Prosthesis

\section{GİRİş}

Poliarileterketon ailesinin yüksek ISI polimeri Polieter eter keton (PEEK), kimyasal adı [- oksi - 1, 4 fenilen - oksi - 1, 4 - fenilen - karbonil - 1, 4 fenilen - ] olup, keton ve eter fonksiyonel grupları ile birbirine bağlı aromatik moleküler zincirlerden oluşan, semikristalin bir termoplastiktir. ${ }^{52}$

Erime ISISI $335^{\circ} \mathrm{C}$ olan yarı kristalize bir materyal olan PEEK için genel sentez yolu; $300{ }^{\circ} \mathrm{C}^{\prime} \mathrm{de}$ difenil sülfon gibi polar bir çözücü içinde hidrokinonun disodyum tuzu ile 4.40-diflurobenzofenon'un reaksiyonudur. ${ }^{34}$

\section{PEEK'İN GENEL ÖZELLİKLERİ}

Yüksek mekanik, fiziksel özelliklere ve aynı zamanda yüksek termal, boyutsal stabiliteye sahip PEEK materyali, birçok endüstri alanında metalik materyallere alternatif olarak görülen ender polimerlerdendir. ${ }^{36}$ Yüksek aşınma direncine sahip olup

*Kırıkkale Üniversitesi Diş Hekimliği Fakültesi, Protetik Diş Tedavisi AD, Kırıkkale.

${ }^{* *}$ Afyon Kocatepe Üniversitesi Diş Hekimliği Fakültesi, Protetik Diş Tedavisi AD, Afyon. 
kimyasal ajanlara dayanıklı bir materyaldir. Kemiğe yakın elastik modülü ile ${ }^{56}$ çiğneme sırasında oluşan kuvvetleri absorbe ederek, bu kuvvetleri servikal bölgedeki peri-implant bölgesinden uzak tutmakta ve krestal kemik rezorpsiyonunu önlemektedir. ${ }^{4}$

PEEK kimyasal olarak inert bir materyaldir. Oda sıcaklığında \% 98'lik sülfürik asit dışında hiçbir geleneksel çözeltide çözünmemektedir. ${ }^{18}$

Gama ve elektron ışını radyasyonuna karşı yüksek direnç gösterir ${ }^{45}$ ve termal özellikleri sayesinde insan vücudu içerisinde stabildir. ${ }^{13}$

Düşük alerjik reaksiyon göstermesi, üstün cilalanabilirliği ve düşük plak afinitesinin olması bu materyalin diğer avantajlarıdır. ${ }^{42}$

PEEK materyali, üstün termal bozunma direncine sahiptir ve erime ısısının $343^{\circ} \mathrm{C}$ olmasından dolayı, $260^{\circ} \mathrm{C}$ çalışma sıcaklığına sahip ortamlarda kullanılabilmektedir. ${ }^{28}$ Örnek verilecek olursa polietilen ve polipropilen gibi yaygın kullanılan polimerlerde kütle kaybına yol açan termal bozulma dereceleri $328^{\circ} \mathrm{C}$ ve $335^{\circ} \mathrm{C}$ arasında iken, PEEK materyalinde bu değer $575^{\circ} \mathrm{C}$ ile $580^{\circ} \mathrm{C}$ arasındadır. ${ }^{38}$

\section{PEEK'İN MEDİKAL KULLANIM ALANLARI}

PEEK, mühendislik alanında popüler yüksek performanslı plastiklerden biridir. Isıya dayanıkılık, çözünmeye direnci, mükemmel elektriksel yalıtım, iyi aşınma direnci ve yüksek yorgunluk direnci gibi üstün mekanik özelliklerinden dolayı, sanayi uygulamaları, havacılık, otomotiv, elektronik, tıbbi ekipman ${ }^{63}$, kimya, petrol, gıda ve içecek endüstrileri de ${ }^{36}$ dahil olmak üzere birçok alanda kullanılmaya başlanmıştır. Tüm bu pozitif özellikleri ile medikal sektörün ilgisini çeken PEEK materyali piyasada bulunan çeşitli kimyasal modifikasyonları ve ticari kompozisyonları ile ortopedik ve nörolojik cerrahi uygulamalar için uygun hale getirilmiştir.9,29,31,39,15 Uygun biyomekanik özellikleri, uzun ömürlü oluşu ve biyouyumluluğu PEEK implantlarını spinal cerrahi uygulamaları için özellikle intervertebral implant materyali olarak ideal hale getirmiştir. 1990'lı yıllardan beri birçok çalışma intervertebral PEEK implantların uzun ömür ve mekanik avantajlarını göstermiştir. ${ }^{16,60}$ Bazı raporlar "minimal" inflamatuar cevap verdiğini belirtmekle birlikte, biyouyumluluk çalışmaları ve yıllarca yapılan klinik takipler materyalin iyi tolere edildiğini göstermiştir. Aşırı duyarlılık veya PEEK ile ilgili alerji vakası bildirilmemiştir. ${ }^{34}$

PEEK'in medikal olarak kullanıldığı diğer bir alan ise kraniofasial deformasyonlardır. ${ }^{41}$ Kraniofasial deformasyonlar için ideal materyal henüz bulunamamasına rağmen PEEK materyali ile iyi sonuçlar elde edilmiştir. 30,10,20,41 Ayrıca karbon fiber takviyeli PEEK materyalinin femur veya tibia fiksasyonu için uygun bir materyal olduğu gösterilmiştir. ${ }^{61}$

\section{PEEK'İN DENTAL KULLANIM ALANLARI}

PEEK diş hekimliğinde geçici abutment, implant materyali, implant destekli bar materyali olarak, sabit protezlerde altyapı materyali, hareketli protezlerde ana bağlayıcı, kroşe ve diğer komponentlerin yapımı için kullanılmaktadır. ${ }^{34,44,46,51-53,64}$

\section{PEEK'in İmplant Materyali Olarak}

\section{Kullanımı}

Wolff yasasına göre kemik, üzerine uygulanan yüke göre yeniden şekillenebilir. İmplant çevresindeki kemikte oluşan streslerin azaltılması, anormal yüklerin azaltılıp normal yüklerin korunmasına olanak sağlayarak implant çevresindeki kemik rezorpsiyonunu önler. ${ }^{34}$

Klinikte sıklıkla kullanılan implantlar; metal, seramik, polimerler ve kompozitler gibi biyomateryallerden üretilebilmektedir. Geçmiş yıllarda, titanyum (Ti) alaşımı, ${ }^{11}$ paslanmaz çelik, ${ }^{3}$ şekil hafızalı alaşım $(\mathrm{NiTi})^{40}$ gibi metalik materyaller yaygın olarak implant yapımında kullanılmıştır. Bunun sebebi; metalik materyallerin uygun mekanik özellikleri, mükemmel sürtünme direnci ve toksik olmamalarıdır. ${ }^{9}$

Bununla birlikte, tıbbi uygulamalarda metalik materyallerin kabulünü engelleyen bazı sınırlamaları da mevcuttur. Birincisi, metal alaşımlarının mukavemeti ve elastik modülü, insan kemik dokusundan çok daha yüksektir. Örneğin, paslanmaz çelik ve titanyum esaslı alaşımların elastik modül değerleri (>100 GPa) insan kemiğinden (10-30 GPa) yüksektir. İnsan kemik dokusu ile metal alaşımlı implantların elastik modülleri arasındaki bu büyük fark, peri-implant dokularda stresin birikmesine, komşu kemik dokularınca absorbe edilmesine ve bunların sonucunda kemik rezorpsiyonu ile protetik başarısızlığa neden olabilmektedir. ${ }^{9}$ Metal alaşımlı implantların bir diğer dezavantajı, radyoopak olup, hastanın X-ışınlı bilgisayarlı tomografi (BT) ve manyetik rezonans görüntüleme (MRI) ile incelenmesini sınırlandırmalarıdır. ${ }^{29}$ Ayrıca Titanyum implantlar koyu renklerinden dolayı estetik problemlere neden olabilmektedir. Bu durum ince mukoza biyotipi olması durumlarında peri-implant yumuşak dokuların grimsi görünümüne neden olabilir. Gülümseme

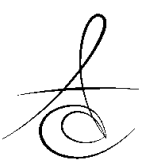


çizgisinin yüksek olduğu hastalarda bu durum sorunlara yol açabilmektedir. ${ }^{46}$

Son yirmi yılda seramik biyomateryallere olan ilgi bir hayli artmıştır. Biyoaktif seramikler, toksik olmayıp, korozyona direnç, iyi biyouyumluluk ve biyoaktivite gibi özellikler sergilemektedir. ${ }^{9}$ Bunun yanında, düşük kırılma direnci, yüksek elastik modül ve kırılganlık gibi mekanik özellikleri seramik implantların dezavantajları arasında sayılabilmektedir. ${ }^{58}$ Alüminyum oksitten üretilen seramik implantların titanyuma alternatif olarak kullanılması önerilmiş; ancak sık kırılma insidansı nedeniyle, bu materyal titanyum implantların yerini alamamıştır. Günümüzde, seramik implantlar renk, mekanik özellikler, biyouyumluluk ve düşük plak afinitesi nedeniyle titanyuma daha iyi bir alternatif gibi görülen zirkonya materyalinden üretilmektedir. Fakat Andreiotelli ve arkadaşları tarafından tarafından yapılan bir sistematik çalışmada, bilimsel klinik verilerin seramik implantları rutin klinik kullanımda önermek için henüz yeterli olmadığını belirtmişlerdir. Ayrıca zirkonya materyali, $210 \mathrm{GPa}$ 'lık yüksek elastik modülünden dolayı, titanyuma kıyasla çevre kemik dokularında daha yüksek strese neden olabilmektedir. ${ }^{46}$

Geleneksel metalik alaşımlı ve seramik implantlarla karşılaştırıldığında, PEEK materyalinden üretilen implantların birçok üstün özelliğe sahip olduğu bildirilmiştir. PEEK ve onun kompozisyonları X-ışınları için radyolusenttir. Titanyum ve seramik implantlarda görülen stresin, önemli ölçüde ortadan kalkması için gerekli olan, insan kemik yapılarına (3-4 GPa) benzer elastik modül ve uygun biyolojik uyumun PEEK implantlarda görüldüğü belirtilmiştir. ${ }^{9}$ Ayrıca karbon fiberler takviyesi ile elastik modül değeri kortikal kemiğinkine daha da yakın bir değer olan 18 GPa'a çıkarılabilir. ${ }^{46}$ PEEK materyali renksizdir (titanyum kaplı veya karbon fiber ile güçlendirilmiş (CFR) formlar hariç). Bu nedenle implant materyali olarak kullanılmasında estetik bir sakınca bulunmamaktadır. ${ }^{46}$

Fakat Schwitalla ve arkadaşlarının ${ }^{47}$ yaptıkları çalışmada karbon fiber takviyeli PEEK ve titanyum dental implantların oblik yük altında kemik implant arayüzünde oluşan stres birikimi değerlendirilmiş ve PEEK materyalinden üretilmiş dental implantların titanyumdan üretilenlere göre daha fazla deformasyona uğradığı ve daha yüksek stres birikimi gösterdiği belirtilmiştir. ${ }^{47}$

PEEK materyalinden üretilmiş dental implantların diş hekimliği cerrahisinde kullanımıyla ilgili komp- likasyonları ve uzun dönem sonuçları hakkında çok az şey bilinmektedir. ${ }^{24}$ PEEK materyalinin mekanik ve biyolojik özelliklerini geliştirmek için bir takım modifikasyonlar yapılmasına rağmen PEEK'ten üretilen dental implantlar klinikte yaygın olarak kullanılmamaktadır. Uzun süreli etkinliklerini tayin edecek yeterli veri yoktur. ${ }^{34}$

\section{PEEK'in Protetik Kullanımı PEEK İmplant Abutment'ları}

Val ve arkadaşları 2016 yılında yaptıkları çalışma ile Titanyum ile güçlendirilmiş PEEK abutment'ların, yüksek biyouyumluluğu göz önüne alındığında konvansiyonel abutment'lara etkin bir alternatif olabileceklerini ve kemik seviyesi ile yumuşak dokunun stabil kalmasını sağlayacaklarını belirtmişlerdir. ${ }^{32}$

Titanyum takviyesi, PEEK abutment'ların direncini arttırırken, implant-abutment uyumluluğunu da arttırmaktadır. ${ }^{32}$

PEEK abutment'lar üzerinde yapılan mekanik testler titanyum abutment'lara benzer sonuçlar vermiştir. Ayrıca histolojik analiz açısından bakıldığında, PEEK abutment'lerin kullanılmasıyla yumuşak doku ile daha uyumlu bir bağlantı sağlanabilmektedir. ${ }^{32}$

Bir PEEK üreticisi olan Juvora'ya (JuvoraLdt., Thornton Cleveleys, Lancashire, İngiltere) göre, abutment vidaları $15 \mathrm{Ncm}$ 'lik bir kuvvet ile torklanmalıdır. ${ }^{48}$ Geleneksel abutment vidaları, titanyum ve titanyum alaşımlarından imal edilmektedir. Bu materyallerden imal edilen bir vidanın bu değerden daha yüksek bir torkla, sıkıştırıması durumunda, PEEK yapısı vidanın yüksek rijitliği (Young modülü: 120GPa) nedeniyle plastik deformasyona uğrayabilmektedir. ${ }^{48} \mathrm{Bu}$ tarz deformasyonlar fonksiyonel çiğneme kuvvetleri ile de güçlendirilebilmektedir. Bu göz önüne alındığında, protezlerin PEEK yapısına benzer elastik özelliklere sahip olması için geleneksel abutment vidalarının PEEK'ten üretilen vidalarla değiştirilmesinin avantajlı olacağı bildirilmiştir. ${ }^{48}$ PEEK materyalinden üretilen vidalar, titanyum vidalarında görülen ve vida kırığına yol açan korozyona uğramamaktadırlar. 5,6,33,50 Titanyum ve titanyum alaşımlarına kıyasla PEEK'in daha düşük sertlik derecesine dayanarak, geleneksel bir implantın iç yivlerinden kaynaklanan materyal aşınmasına maruz kalma riskinin azaldığı varsayılabilir. ${ }^{43}$ Abutment vidasının kırılması durumunda, implantın içinde kalan parçanın çıkarılması da daha kolay olacaktır. ${ }^{36}$ 
Schwitalla ve arkadaşlarının 2016 yılında PEEK'ten üretilen abutment vidalarının gerilim kuvvetini incelemek ve bunları abutment vidalarının mekanik gereksinimleriyle ilişkilendirmek amacıyla yaptıkları çalışmada, PEEK'ten üretilen 1,6 mm'lik bir abutment vidasının, en az \%50 oranında karbon fiber takviyesi ve karbon fiberlerin vidanın dış konturlarında çok yönlü olarak dizilmeleri durumunda kullanılabileceği belirtilmiştir. PEEK'in diğer çeşitlerinden üretilen vidaların ise mekanik gereksinimleri yerine getirebilmesi için daha büyük boyutlarda üretilmesi gerektiği belirtilmiştir. ${ }^{48}$

2014 yılında Neumann ve arkadaşları ${ }^{36}$ yaptıkları çalışmada, titanyum abutment vidalarına kıyasla, PEEK abutment vidalarının kırılmaya karşı daha dirençli olduğunu göstermişlerdir.

PEEK materyalinin biyouyumluluğu göz önünde bulundurarak, iyileşme başlıkları da PEEK'ten üretilebilmektedir. Koutouzis ve arkadaşları tarafından gerçekleştirilen bir randomize kontrollü klinik çalışmada, PEEK ve Titanyum abutment'ların çevresinde yumuşak doku inflamasyonu ve kemik rezorpsiyonu arasında önemli bir fark olmadığı öne sürülmüştür. ${ }^{27}$ Ayrıca PEEK abutment'larının oral mikrobiyal flora afinitesi titanyum, zirkonya abutment'larla benzerdir. ${ }^{19}$

\section{PEEK'in Hareketli Bölümlü Protezlerde Kullanımı}

Krom kobalt materyalinden üretilen iskelet bölümlü protezler, parsiyel dişsiz hastaların rehabilitasyonu için ucuz ve öngörülebilir bir tedavi seçeneğidir. Metal kroşelerin estetik olmayışı, protezin artan ağırığı, metalik tat ve metal alaşımlarına karşı alerjik reaksiyonlar, klinik uygulamada Poliamid ve Asetal Rezinler gibi bir dizi termoplastik materyalin ortaya çıkmasına yol açmıştır. Poliamid materyalleri, düşük elastik modüllerinden dolayı, dayanak dişler üzerindeki rotasyonel kuvvetleri azaltmalarının yanı sıra estetiktirler. Poliamid materyalinden üretilmiş, hareketli bölümlü protezlerin (özellikle Kennedy sınıf I ve II vakalar) en büyük dezavantajları, oklüzal gömülmeye neden olabilen, oklüzal tırnak eksikliği, rijit alt yapılar olmamaları ve astarlama prosedürlerindeki yetersizlikleridir. ${ }^{64}$ Asetal Rezinler ise, retantif kroşeler, konnektörler ve destekleyici unsurlarla, Poliamidlere kıyasla daha rijit bir alt yapı oluşturmakta, yeterli mekanik mukavemeti sunmaktadırlar. Ancak, Asetal Rezinlerin doğal saydamlığı ve canlılığı bulunmamaktadır. 3,12,14,22 $\mathrm{Bu}$ iki materyale alternatif olarak PEEK materyali de, hareketli bölümlü protezlerde alt yapı materyali olarak kullanılmaya başlanmıştır. ${ }^{64}$

PEEK materyalinin beyaz rengi, geleneksel metal alt yapılarınkine kıyasla daha üstün bir estetik sağlamaktadır. ${ }^{64} \mathrm{Bu}$ materyalin diğer avantajları, alerjik reaksiyonların ve metalik tadın ortadan kaldırılması, yüksek cilalama kalitesi, düşük plak afinitesi ve iyi aşınma direncidir. ${ }^{1,25,35,49}$

Tüm bu üstün özelliklerine rağmen Tannous ve arkadaşları $^{57}$ PEEK materyalinden üretilmiş kroşelerin, Kobalt-Krom (Co-Cr) kroşelere kıyasla daha düşük retantif kuvvete sahip olduğunu bildirmişlerdir. ${ }^{57}$

PEEK materyalinin diğer bir uygulama alanı ise, çıkarılabilir obturatör olarak kullanılmasıdır. ${ }^{37}$ Ancak, geleneksel akrilik protezlere kıyasla PEEK obturatörlerin etkinliğini değerlendirmek için daha fazla çalışmaya intiyaç vardır. ${ }^{34}$

\section{PEEK'in Sabit Bölümlü Protezlerde}

\section{Kullanımı}

PEEK materyali, tek eksenli gerilim, ve sıkıştırma kuvvetleri karşısında deformasyonlara karşı koyabilmekte ve 1383 N'a kadar olan sıkıştırma kuvvetlerine dayanabilmektedir. (Plastik deformasyon yaklaşık 1200 N'den başlar). Waltimo ve arkadaşlarına göre, molar bölgede 909 N'luk maksimum ısırma kuvveti görüldüğünden, PEEK materyali kron ve köprü restorasyonları için uygun bir alt yapı materyali olarak görülmektedir. ${ }^{51}$

Stawarczyk ve arkadaşlarının ${ }^{52}$ yapmış oldukları çalışmada, 7.4 mm²'lik konektör çapına sahip, veneerlenmemiş 3 üyeli PEEK köprülerde 1200 N'da deformasyon ve 1385 N'da konnektörde kırılma gösterilmiştir. Bu nedenle PEEK materyali, sabit protezler için bir altyapı materyali olarak önerilmektedir. ${ }^{52}$

PEEK materyalinin diş hekimliği pratiğinde protetik uygulamalarda kullanım sebeplerinin bazıları aşağıda listelenmiştir;

* Daha hafif bir restorasyon

* Kemiğe daha yakın elastikiyet

* Şok absorbe etme özelliği

* Metalsiz restorasyon

* Korozyon gözlenmemesi

* Daha düşük yorgunluk

* Yüksek biyouyumluluk

* Düşük plak afinitesi ${ }^{34}$

PEEK materyali opaktır ve genellikle beyaz ya da gri renge sahiptir. Renginden dolayı estetik bölgede

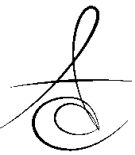


monolitik olarak kullanılamaz ve mutlaka veneerlenmesi gerekmektedir. ${ }^{59}$

\section{PEEK'İN DİĞER PROTETİK MATERYALLERE GÖRE ÜSTÜN ÖZELLİKLERİ}

Alümina gibi yüksek sertlikteki materyaller oklüzal kuvvet iletimi esnasında restorasyonun ve dayanak dişlerin biyomekanik özelliklerini olumsuz yönde etkileyebilmektedir. ${ }^{64}$ PEEK ve kompozit rezinler gibi daha düşük elastik modüle sahip materyallerin ise, stres kıııcı gibi davranarak oklüzal stresi azalttığı bildirilmiştir. ${ }^{17,37}$ PEEK, 4GPa değerindeki elastik modülü kuvvet iletimini azaltarak endodontik tedavi görmüş dişlerde dişin ve kökün aşırı yüklenmesi ile oluşacak kırılmayı önleyebilmektedir. ${ }^{64}$

Stawarczyk ve arkadaşları 2015 yilında yaptıkları çalışma ile CAD / CAM ile kazınmış PEEK alt yapılı sabit protezler için 2.354 N'luk kırılma dayanımını belirtmişlerdir. ${ }^{52}$ Üretici firma, CAD / CAM ile kazınmış üç üyeli, PEEK altyapılı kompozit rezinle veneerlenmiş sabit protezlerde kırıma dayanımın 2,055 N olarak belirtmiştir. ${ }^{21}$ Bu değerler Lityum Disilikat Cam-Seramik $(950 \mathrm{~N}){ }^{23}$ In-Ceram Alumina $(851 \mathrm{~N}){ }^{7}$ In-Ceram Zirkonya $(841 \mathrm{~N})^{7}$ ve Zirkonya $(981-1331 \mathrm{~N})^{26}$ için belirtilen değerlerden daha yüksektir.

Tıpta ve diş hekimliğinde kullanılan metalik materyaller birçok dezavantaja sahiptir. Bunlardan bazılarl:

- Kemik ile karşılaştırıldığında daha yüksek elastik modül,

- Metal iyonlarının muhtemel salınımı (Galvanik akım),

- BT ve MR taramalarında artefaktlara sebep olmalarıdır. ${ }^{36}$

PEEK'in metal alaşımlarına göre üstün özellikleri/avantajları:

- Hafif oluşu

- Kemiğe benzer elastik modülü

- Korozyon miktarının düşük olmasıdır. ${ }^{36}$

Metal ve zirkonyum gibi materyallerin elastikiyeti az olduğu için oluşan aşıı stresler protez kırıklarına, TME problemlerine, implant ve diş çevresindeki destek dokularda hasara neden olabilmektedir. Dolayısıyla PEEK'in şok absorbe etme özelliği, implant ve diş destekli köprüler ve kronlar için istenen bir özelliktir. ${ }^{36}$

Ayrıca PEEK; biyouyumluluğu, alerjen olmayışı, korozyon direnci ve mekanik özelliklerinden ötürü titanyum, Cr-Co gibi metalik materyallerin yerine diş ve implant destekli sabit protezlerde kullanilabilmektedir. $^{42}$

\section{SONUÇ}

Son zamanlarda PEEK biomateryalleri ile ilgili yapılan araştırmalar artmış ve gelecek için umut vaad eder hale gelmiştir. ${ }^{62}$

A.Kürşad Çulhaoğlu: ORCID ID: . 0000-0002-2396-2355

Serhat Emre Özkır: ORCID ID: 0000-0001-5952-240X

Fatoş Türkkal: ORCID ID: 0000-0003-2132-2116

\section{KAYNAKLAR}

1. Adler S, Kistler S, Kistler F. Compression-moulding rather than milling: a wealth of possible applications for high performance polymers. Quintessenz Zahntechnik 2013;39:376-84.

2. Agarwal R, Gonzalez-Garcl C, Torstrick B, Guldberga RE, Salmeron-Sanchez M, Garcl AJ. Simple coating with fibronectin fragment enhances stainless steel screw osseoin- tegrationin healthy and osteoporoticrats. Biomaterials 2015;63:13745.

3. Arda T, Arikan A. An in vitro comparison of retentive force and deformation of acetal resin and cobalt-chromium clasps. J. Prosthet Dent 2005; 267-74.

4. Asvanund P, Morgano SM. Photoelalastic stress analysis of external versus internal implantabutment connections. J Prosthet Dent 2011;106: 266-71.

5. Barao VA, Mathew MT, Assuncao WG, Yuan JC, Wimmer MA, Sukotjo C. Stability of cp-ti and ti6al-4 valloy for dental implants as a function of saliva ph-an electro chemical study. Clin Oral Implant Res 2012; 23: 1055-62.

6. Barao VA, Yoon $\mathrm{CJ}$, Mathew MT, Yuan JC, Wu CD, Sukotjo C. Attachment of porphyromon as gingivalis to corroded com- mercially pure titanium and titanium-aluminum-vanadium alloy. J Periodontol 2014;85:1275-82.

7. Beuer F, Steff B, Naumann M, Sorensen JA. Loadbearing capacity of all-ceramic three-unit fixed partial dentures with different computer-aided design (CAD)/ computer-aided manufacturing (CAM) fabricated materials. Eur J Oral Sci 2009; 116: 381-6. 
8. Camarini E, Tomeh J, Dias R, Da Silva E. Reconstruction of frontal bone using specific implant polyether-ether-ketone. J Craniofac Surg 2011; 22:2205-7.

9. Chen F, Gatea S, Ou H, Lu B, Long H. Fracture characteristics of PEEK at various stress triaxialities. J Mech Behav Biomed Mater 2016; 64:173-86.

10. Cho DY, Lee WY, Sheu PC. Treatment of multilevel cervical fusion with cages. Surg Neurol 2004; 62: 378-85.

11. Diefenbeck M, Muckley T, Schrader C, Schmidt J, Zankovych S, Bossert J, Jandt KD, Faucon M, Finger $U$. The effect of plasma chemical oxidation of titanium alloy on bone- implant contact in rats. Biomaterials 2011; 32: 8041-7.

12. Donovan TE, Cho GC. Esthetic considerations with removable partial dentures. J Calif Dent Assoc 2003; 31: 551-7.

13. Fan JP, Tsui $C P$, Tang $C Y$, Chow $C L$. Influence of interphase layer on the overall elasto-plastic behaviors of ha/PEEK biocomposite. Biomaterials 2004; 25: 5363-73.

14. Fueki K, Ohkubo C, Yatabe M. Clinical application of removable partial dentures using thermoplastic resin-part I: definition and indication of non-metal clasp dentures. J Prosthodont Res. 2014; 58: 3-10.

15. Gok H, Onen MR, Yıldırım H, Gulec I, Naderi S. Empty Bladed PEEK Cage For Interbody Fusion After Anterior Cervical Discectomy. Turk Neurosurg 2016;26:105-10

16. Gornet MF, Chan FW, Coleman JC, Murrell B, Nockels RP, Taylor BA, Ochoa JA. Biomechanical assessment of a PEEK rod system for semi-rigid fixation of lumbar fusion constructs. J Biomech Eng. 2011; 133: 081009.

17. Gracis S, Nicholls JI, Chalupnik JD, Yuodelis RA. Shock absorbing behavior of five restorative materials used on implants. Int J Prosthodont 1991; 4: 282-91.

18. Ha WS, Hauert R, Ernst HK, Wintermantel E. Surface analysis of chemicallyetched and plasmatreated polyether ether ketone (PEEK) for biomedical applications, surface coatings technology 1997; 96: 293-9.
19. Hahnel S, Wieser A, Lang R, Rosentritt M. Biofilm formation on the surface of modern implant abutment materials. Clin Oral Implants Res. [epub ahead of print], 2014.

20. Hee HT, Kundnani V. Rationale for use of polyether ether ketone polymer interbody cage device in cervical spine surgery. Spine J 2010; 10 : 66-9.

21. Invibio Biomaterial Polymer Solutions. New material options for innovation in restorative and prosthetic dentistry, 2011.

22. Ito $M$, Wee AG, Miyamoto $T$. The combination of a nylon and traditional partial removable dental prosthesis for improved esthetics: a clinical report. J Prosthet Dent 2013; 109: 5-8.

23. Ivoclar Vivadent. Lithium disilicate (LS2) scientific report, 2011.

24. Khonsari RH, Berthier $P$, Rouillon T, Perrina JP, Crre P. Severe infectious complications after PEEKderived implant placement: report ofthree cases. J Oral Maxillofac Surg Med Pathol 2014; 26: 477-82.

25. Kistler F, Adler S, Kistler S. PEEKhochleistungskuns tstoffeimimplantat-prothetis chen workflow. Implantologie J 2013; 7: 17-42.

26. Kolbeck C, Behr M, Rosentritt M, Handel G. Fracture force of tooth-tooth- and implant-toothsupported all-ceramic fixed partial dentures using titanium vs. customised zirconia implant abutments. Clin Oral Implants Res 2008; 19: 104953.

27. Koutouzis T, Richardson J, Lundgren T. Comparative soft and hard tissue responses to titanium and polymer healing abutments. J Oral Implantol 2011; 37: 174-82.

28. Kuo MC, Tsai CM, Huang JC, Chen M. PEEK composites reinforced by nano-sized $\mathrm{SiO}^{2}$ and $\mathrm{Al}^{2} \mathrm{O}^{3}$ particulates. Mater Chem Phys 2011; 90: 185-95

29. Kurtz SM, Devine JN. PEEK biomaterials in trauma, orthopedic, and spinal implants. Biomaterials 2007; 28: 4845-69.

30. Lethaus B, Safi $Y$, Ter Laak-Poort $M$, KlossBrandstatter A, Banki F, Robbenmenke C, Kessler P. Cranioplasty with customized titanium and PEEK implants in a mechanical stress model. J Neurotrauma 2012; 29: 1077-83. 
31. Maharaj G, Bleser S, Albert K, Lambert R, Jani S, Jamison R. Characterization of wear in composite material orthopaedic implants. part I: the composite trunnion/ceramic head interface. Biomed Mater Eng 1994; 4: 193-8.

32. Mate Sanchez De-Val JE, Gomez-Moreno G, Martınez CP, Fernandez MP, Marın JM, Gehrke SA, Calvo-Guirado JL. Peri-implant tissue behavior around non-titanium material: experimental study in dogs. ann. anat. http://dxdoi. org/10.1016/j.aanat.2016.03.005, 2016.

33. Mathew MT, Abbey S, Hallab NJ, Hall DJ, Sukotjo C, Wimmer MA. Influence of ph on the tribocorrosion behavior of cpti in the oral environment: synergistic inter- actions of wear and corrosion. J Biomed Mater Res B Appl Biomater 2012; 100: 1662-71.

34. Najeeb S, Zafar MS, Khurshid Z, Siddiqui F. Applications of polyether ether ketone (PEEK) in oral implantology and prosthodontics. J Prosthodont Res 2016; 60: 12-9.

35. Neugebauer J, Adler S, Kisttler F. The use of plastics in fixed prosthetic implant restoration. Zwr- German Dent J 2013; 122: 242-5.

36. Neumann EA, Villar CC, Franca FM. Fracture resistance of abutment screws made of titanium, polyetheretherketone, and carbon fiber-reinforced polyether ether ketone. Braz Oral Res 2014; 28: 15.

37. Palau CS, Nicolas TJ, Barbera BM, Termes CJ. Use of poly ether ether ketone in the fabrication of a maxillary obturator prosthesis: a clinical report. ] Prosthet Dent 2014; 112: 680-2.

38. Patel P, Hull T, Cabe RW, Flath D, Grasmeder J, Percy $M$. Mechanism of thermal decomposition of poly(ether ether ketone) (PEEK) from a review of decomposition studies. Polym Degrad Stabil 2010; 95: 709-18.

39. Pokorny D, Fulin P, Slouf M, Jahoda D, Landor I, Sosna A. Polyether ether ketone (PEEK). part II: application in clinical practice. Acta Chir Orthop Traumatol cech 2010; 77: 470-8.

40. Poon RWY, Yeung KWK, Liu XY, Chu PK, Chung $\mathrm{CY}$, Lu WW, Cheung KMC, Chan D. Carbon plasma immer- sion ion implantation of nickel-titanium shape memory alloys. Biomaterials 2005; 26: 2265-72.
41. Rodriguez, E. Poly ether ether ketone custommade implants for cranio facial defects: report of 14 cases and review of the literature. J Craniomaxillofac Surg 2015; 43: 1232-8.

42. Rubert SC, Calas MD, Barberá A. Analysis of the feeding system in the injection process of PEEK in fixed partial dentures. Procedia Eng 2015; 132: 1021-8.

43. Sampaio M, Buciumeanu M, Henriques B, Silva FS, Souza JC, Gomes JR. Tribocorrosion behavior of veneering biome- dical PEEK to $\mathrm{Ti}^{6} \mathrm{Al}{ }^{4} \mathrm{~V}$ structures. j. mech. Behav Biomed Mater 2016; 54: 123-30.

44. Sarot JR, Contar CM, Cruz AC, Desouza magini R. Evaluation of the stress distribution in cfr-PEEK dental implants by the three-dimensional finite element method. J Mater Sci Mater Med 2010; 21: 2079-85.

45. Sasuga TH, Hagiwara M. Radiation deterioration of several aromatic polymers under oxidative conditions. Polymer 1987; 28: 1915-21.

46. Schwitalla A, Muller WD. PEEK dental implants: a review of the literature. J Oral Implantol 2013; 39: 743-9.

47. Schwitalla AD, Abou-Emara $M$, Spintig $T$, Lackmann J, Muller WD. Finite element analysis of the biomechanical effects of PEEK dental implants on the peri-implant bone. J Biomech 2015; 48: 17.

48. Schwitalla $A D$, Abou-Emara $M$, Zimmermann $T$, Spintig T, Beuer F, Lackmann J, Muller WD. The applicability of PEEK-based abutment screws. J Mech Behav Biomed Mater 2016; 63: 244-51.

49. Siewert B, Parra M. A new group of material in dentistry. PEEK as a framework material used in 12-piece implant-supported bridges. Z Zahnarzt Implantol 2013; 29: 148-59.

50. Souza JCM, Barbosa SL, Ariza E, Celis JP, Rocha LA. Simultaneous degradation by corrosion and wear of titanium in artificial saliva containing fluorides. Wear 2012; 292-293: 82-8.

51. Sproesser O, Schmidlin PR, Uhrenbacher J, Eichberger M, Roos M, Stawarczyk B. Work of adhesion between resin composite cements and PEEK as a function of etching duration with sulfuric acid and its correlation with bond strength values. International J Adhves Adhes 2014; 54: 184-90. 
52. Stawarczyk B, Eichberger M, Uhrenbacher J, Wimmer T, Edelhoff D, Schmidlin PR. Three-unit reinforced poly ether ether ketone composite fdps: influence off abrication method on load bearing capacity and failure types. J Dent Mater 2015; 34: 7-12.

53. Stawarczyk B, Bahr N, Beuer F, Wimmer T, Eichberger M, Gernet W, Schmidlin PR. Influence of plasma pretreatment on shear bond strength of self-adhesive resin cements to polyetheretherketone. Clin Oral Investig 2014; 18: 163-70.

54. Stawarczyk B, Ender A, Trottmann A, Ozcan M, Fischer J, Hämmerle $\mathrm{CH}$. Load-bearing capacity of cad/cam milled polymeric three-unit fixed dental prostheses: effect of aging regimens. Clin Oral Investig 2012; 16: 1669-77.

55. Stawarczyk B, Sener B, Trottmann A, Roos M, Ozcan $\mathrm{M}$, Hämmerle $\mathrm{CH}$. Discoloration of manually fabricated resinsand industrially fabricated cad/cam blocks versusglass-ceramic: effect of storage media, duration, and subsequent polishing. Dent Mater J 2012; 31: 377-83.

56. Steinberg EL, Rath E, Shlaifer A, Chechik O, Maman $E$, Salai $M$. Carbon fiber reinforced PEEK optima- a composite material biomechanical properties and wear/debris characteristics of cfPEEK composites for orthopedic trauma implants. J Mech Behav Biomed Mater 2013; 17: 221-8.

57. Tannous F, Steiner M, Shahin R, Kern M. Retentive forces and fatigue resistance of thermoplastic resin clasps. Dental Mater 2012; 28: 273-8.

58. Taskonak B, Mecholsky JR, Anusavice KJ. Residual stresses in bilayer dental ceramics. Biomaterials 2006; 26: 3235-41.

59. Taufall S, Eichberger M, Schmidlin PR, Stawarczyk B. Fracture load and failure types of different veneered polyetheretherketone fixed dental prostheses. Clin Oral Investig 2016; 20: 2493-500.

60. Turner J, Paller D, Murrell C. The mechanical effect of commercially pure titanium and poly ether ether ether ketone rods on spinal implants at the operative and adjacent levels. Spine 2010; 35: 1076-82.
61. Wang L, Weng L, Song S, Zhang Z, Tian S, Ma R. Characterization of polyether ether ketonehydroxyapatite nanocomposite materials. Mater Sci Eng 2011; 528: 3689-96.

62. Williams D. New horizons for thermoplastic polymers. Med Device Technol. 2001; 12: 8-9.

63. Zhou L, Qian Y, Zhu Y, Liu H, Gan K, Guo J. The effect of different surface treatments on the bond strength of PEEK composite materials. Dent Mater 2014; 30: 209-15.

64. Zoidis P, Bakiri E, Polyzois G. Using modified polyetheretherketone (PEEK) as an alternative material for endocrown restorations: a short-term clinical report. J Prosthet Dent 2017; 117: 335-9.

\author{
Yazışma Adresi \\ Yrd. Doç. Dr. Ahmet Kürşad ÇULHAOĞLU \\ Kırıkkale Üniversitesi \\ Diş Hekimliği Fakültesi, \\ Protetik Diş Tedavisi Anabilim Dalı, \\ KIRIKKALE \\ e-posta: ahmetculhaoglu@hotmail.com
}

